\title{
TECNOLOGIAS DIGITAIS NA INFÂNCIA: REFLEXÕES A PARTIR DA PERCEPÇÃO DAS FAMÍLIAS
}

\section{DIGITAL TECHNOLOGIES IN CHILDHOOD: REFLECTIONS FROM FAMILIES PERCEPTION}

\section{Martina Gomes Apolinário ${ }^{1}$}

Graziela Fátima Giacomazzo

\begin{abstract}
RESUMO: As tecnologias estão cada vez mais presentes no cotidiano das crianças, que crescem e se desenvolvem junto com estes recursos. O objetivo geral deste artigo é analisar quais as interações que as crianças de 4 a 5 anos estabelecem no uso dos recursos tecnológicos digitais a partir do enfoque das famílias; e como objetivos específicos: identificar quais os recursos tecnológicos crianças entre 3 a 5 anos tem acesso; identificar como ocorre o acesso aos recursos tecnológicos na infância e compreender a percepção dos pais sobre o uso de tecnologias digitais na infância. A presente pesquisa é de cunho qualitativo, de caráter exploratório, bibliográfica, e de campo, e teve como instrumento de pesquisa um questionário aplicado com 11 pais de alunos da Educação Infantil de 4 a 5 anos, especificamente de uma turma do pré-escolar da mesma instituição de ensino particular de Criciúma. As respostas foram analisadas em 4 eixos: brinquedos e brincadeiras preferidos; crianças e suas tecnologias: recursos e seus dispositivos; acesso a tecnologia; percepção das contribuições pelas famílias. Foram utilizados os seguintes autores para o referencial teórico Aries (1981), Amante (2011), Volpato (2002), entre outros. A partir desta pesquisa conclui-se que os pais apesar da preocupação com o uso em excesso destes recursos, percebem e reconhecem a importância do uso dos mesmos para o desenvolvimento de seus filhos.
\end{abstract}

PALAVRAS CHAVE: Infância. Tecnologias. Brinquedos. Educação Infantil.

ABSTRACT: Technologies are increasingly present in children's daily lives, which grow and develop along with these resources. The general objective of this article is to analyze the interactions that children from 4 to 5 years of age establish in the use of digital technological resources based on the families' approach; and as specific objectives: to identify which technological resources children between 3 and 5 years old have access; to identify how the access to technological resources in childhood occurs and to understand the perception of parents about the use of digital technologies in childhood. The present research is qualitative, exploratory, bibliographic, and field, and had as a research instrument a questionnaire applied to 11 parents of children from 4 to 5 years of age, specifically from a pre-school institution of Criciúma. The answers were analyzed in 4 axes: toys and favorite games; children and their

\footnotetext{
${ }^{1}$ Graduanda em Pedagogia Licenciatura/ UNESC. gfg@unesc.net

2 Pedagoga, Doutora em Educação, Docente no Curso de Pedagogia e PPGE da UNESC. gfg@unesc.net

Saberes Pedagógicos, Criciúma, v. 3, nº1, janeiro/junho 2019.- Curso de Pedagogia- UNESC
} 
technologies: resources and their devices; access to technology; perception of contributions by households. The following authors were used for the theoretical reference Aries (1981), Amante (2011), Volpato (2002), among others. Based on this research, it is concluded that parents, despite their concern over the excessive use of these resources, perceive and recognize the importance of using these resources for the development of their children.

KEYWORDS: Childhood. Technologies. Toys. Early Childhood Education.

\section{INTRODUÇÃO}

No decorrer do Estágio não-obrigatório na educação infantil e no convívio diário com crianças fora do ambiente escolar, o contato me fez perceber a interação das crianças com diversos recursos tecnológicos e a facilidade com que interagiam e os manuseavam. A partir dessas observações surgiu a curiosidade de compreender o quanto o uso desses recursos pode ou não contribuir para o desenvolvimento das crianças e se os pais percebiam o uso desses recursos de maneira positiva ou não. Esta pesquisa traz como problema a seguinte questão: "Quais interações as crianças de 4 a 5 anos estabelecem no uso dos recursos tecnológicos digitais a partir do enfoque das famílias? ". 

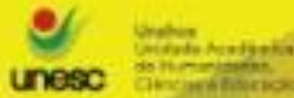

unesc

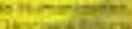

Diante deste problema o objetivo geral foi identificar as interações que as crianças de 4 a 5 anos estabelecem no uso dos recursos tecnológicos digitais, tendo como objetivos específicos: identificar quais os recursos tecnológicos crianças entre 4 a 5 anos tem acesso; identificar como ocorre o acesso aos recursos tecnológicos na infância e compreender a percepção das famílias sobre o uso de tecnologias digitais na infância.

Portanto, para responder ao problema, foram entregues questionários a 11 pais e a partir de então dado inicio a escrita do referencial teórico, dividido pelos seguintes capítulos: "Infância, brinquedos e brincadeiras", que fala sobre o conceito e mudanças na infância no decorrer dos anos e a importância dos brinquedos e brincadeiras, e "Infância e Educação Infantil na cultura digital", mostrando a inserção da cultura digital na escola e no cotidiano das crianças. Já a analise de dados foi divida em quatro eixos que são: Brinquedos e brincadeiras preferidos; Crianças e suas tecnologias: recursos e seus dispositivos; acesso a tecnologia; Percepção das contribuições pelos pais.

Os autores que contribuíram para a pesquisa e construção do referencial teórico foram Aries (1981), Amante (2011), Volpato (2002), entre outros.

\section{INFÂNCIA, BRINQUEDOS E BRINCADEIRAS}

O conceito de infância sofreu muitas alterações de grande significado ao longo de toda a história. Antigamente a criança não tinha significado algum para a sociedade, as condições precárias de higiene e saúde eram fatores de grande contribuição para a alta taxa de mortalidade na época. Meninos e meninas recebiam tratamentos diferentes a ponto de as meninas serem tratadas apenas como produto sexual.

Segundo Aries (1981), as crianças eram "paparicadas" somente nos primeiros anos de vida, enquanto ainda eram engraçadinhas. Se divertiam com uma criança tanto quanto com um macaquinho, e se ela morresse na maioria das vezes era dado nenhuma importância, pois logo outra criança iria a substituir

As crianças não possuíam identidade própria, só se destacavam a partir do momento em que conseguiam ter atitudes muito semelhantes com a dos adultos. Criadeiras e 
amas de leite eram quem cuidavam dessas crianças, sendo assim não era necessária nenhuma preparação para que pudessem exercer esse papel.

\begin{abstract}
A descoberta da infância começou sem dúvida no século XIII, e sua evolução pode ser acompanhada na história da arte e na iconografia dos séculos XV e XVI. Mas os sinais de seu desenvolvimento particularmente numerosos e significativos a partir do fim do século XVI e durante o século XVII. (ARIÉS, 1981 p. 65).
\end{abstract}

Com o passar do tempo, o conceito de infância foi mudando, a criança passou a ter lugar de importância na sociedade e na família, foi percebendo o quanto elas necessitavam de tempo, espaço e cuidados para que pudessem então crescer e se desenvolver de maneira saudável. A partir daí cada vez mais a criança foi ganhando espaço e assim contribuindo para as mudanças do conceito de infância e chegando ao que temos hoje.

Com todas essas mudanças ocorridas, aos poucos foram surgindo instituições que tinham como função cuidar de crianças pequenas, no início era um local só para deposito de crianças, as famílias deixavam seus fillhos só para serem "cuidados", ainda não se falava em cuidar e educar, e as professoras eram como babás as "tias", nesse local as crianças passavam o tempo em que seus pais trabalhavam.

Quando os brinquedos surgiram para as crianças ele não servia para "todas" as crianças, e sim para as crianças filhas da elite. As crianças pobres não tinham o direito de estudar e brincar, somente trabalhar.

Muitos dos mais antigos brinquedos (a bola, o papagaio, o arco, a roda de penas) foram impostas ás criança, de certa forma, como objetos de culto, e somente mais tarde, devido á força de imaginação das crianças, transformados em brinquedos. (BENJAMIM, 1984, p.19, apud VOLPATO, 2002.)

Vale ressaltar também dos diversos tipos de brincadeiras e a importância e significado que trazem para a infância. Segundo Kishimoto (2001), o jogo de faz de conta tem grande importância comprovada por pesquisas no desenvolvimento cognitivo, afetivo e social. Segundo Maluf (2004), ao se relacionar com lembranças do passado e do presente através de brincadeiras em grupo, o indivíduo pode assim dar sentido ao seu mundo, a sua existência. Mostrando assim que brincar é uma necessidade interna tanto da criança quanto do adulto, a necessidade de brincar é inerente ao seu desenvolvimento.

Saberes Pedagógicos, Criciúma, v. 3, nº1, janeiro/junho 2019.- Curso de Pedagogia- UNESC 
Brincar é tão importante quanto estudar, ajuda a esquecer momentos difíceis. Quando brincamos, conseguimos sem muito esforço encontrar respostas a varias indagações, podemos sanar dificuldades de aprendizagem, bem como interagimos com nossos semelhantes. (MALUF, 2004, p.19).

Percebemos a importância que o brinquedo e a brincadeira tem na infância, pois através dessas interações as crianças conseguem se expressar, conseguem não só se distrair, mas também aprender de maneira lúdica no convívio com os demais, conseguem lidar e resolver conflitos, sem contar no quanto as brincadeiras estimulam a criatividade e imaginação.

No ato do brincar, os papeis são desenhados com muita clareza: a menina torna-se mãe, professora, tia, comadre e irmã; por sua vez, o menino torna-se pai, motorista, índio, policia e ladrão. Dessa forma, as crianças procuram nos brinquedos, principalmente naqueles que são miniaturas de objetos de adultos, imitar os papéis sociais estabelecidos na prática cotidiana. (VOLPATO, 2017, p.78)

Sendo assim é importante considerar, o quão importante e significativo são os brinquedos e brincadeiras na infância, tendo em vista que são através dessas interações que conseguem se expressar, se desenvolver e se relacionar com pessoas e objetos ao seu redor.

\subsection{Infância e educação infantil na cultura digital.}

A cultura digital vem se mostrando cada vez mais presente no nosso dia a dia, e cada vez mais utilizamos dela sem nem perceber. Tecnologia e educação andam juntas, uma precisa da outra. Para que essa integração venha a acontecer, conhecimento, hábitos, comportamentos precisam ser estudados para que possamos aprender e assim fazer o uso adequado destes recursos, ou seja, precisamos da educação e conhecimento para aprendermos a utilizar as tecnologias.

Uma vez assimilada a informação sobre a inovação, nem a consideramos mais tecnologia. Ela se incorpora ao nosso universo de conhecimentos e habilidades e fazemos uso dela na medida de nossas possibilidades e necessidades. (KENSKI, 2007, p.44).

Saberes Pedagógicos, Criciúma, v. 3, nº1, janeiro/junho 2019.- Curso de Pedagogia- UNESC 


\title{
A partir do momento que conseguimos compreender o conhecimento e utilização
} da tecnologia, ou seja, a partir do momento que aprendemos sobre determinada tecnologia, ela começa a fazer parte do nosso cotidiano e a utilizamos de maneira automática, desse modo devemos utilizar assim com as crianças, trazer a tecnologia como recurso, para que junto das aprendizagens e conhecimentos que já possuem possam desenvolver outras, e que após compreendido venham a fazer parte de seu dia a dia.

\begin{abstract}
Pense um pouco em quantos processos e produtos você usa naturalmente em seu cotidiano e em como teve de se esforçar para aprender a utiliza-los. Talvez você já nem os perceba como "tecnologia" que, em um determinado momento, revolucionaram sua maneira de pensar, sentir e agir. Muitas outras pessoas, como você, passaram por esse mesmo processo, incorporaram inovações na sua vida e, hoje, não conseguem mais viver sem elas. Assim podemos ver que existe uma relação direta entra educação e tecnologias. Usamos muitos tipos de tecnologias para aprender e saber mais e precisamos da educação para aprender e saber mais sobre as tecnologias. (TAVARES, 2011, p.44).
\end{abstract}

Devemos partir do interesse das crianças para que elas despertem curiosidade e assim consigamos obter nossos objetivos estabelecidos. Nos dias de hoje a maioria das crianças tem contato com a tecnologia em casa, seja com smartphone, computador, tablets ou videogame, os/as professores/as então devem conhecer a realidade do/a aluno/a e assim trazer para seu cotidiano essas tecnologias a fim de ser um complemento no seu trabalho e uma ferramenta de ensino.

Já com relação a utilização de recursos tecnológicos no ambiente escolar ou ate mesmo no ambiente familiar, segunda Amante (2011) e outros, pode ser que a utilização dos mesmos desencadeie uma onda de entusiasmo devido ao fato de ser uma novidade, mas o uso de recursos tecnológicos não diminui o uso de materiais tradicionais, nem a procura por outras atividades. Passado o período inicial, passam a ser vistos como um recurso como qualquer outro.

Antes da chegada da cultura digital nas casas e escolas, os brinquedos e as brincadeiras foram se modificando ao longo do tempo, alguns ainda podem ser vistos do seu modo original, outros foram modificados e outros nem existem mais e talvez nossa sociedade nem chegou a conhecer. (VOLPATO, 2002, p.16).

Saberes Pedagógicos, Criciúma, v. 3, nº1, janeiro/junho 2019.- Curso de Pedagogia- UNESC 
O uso de recursos tecnológicos desde que utilizados com objetivos e sem excessos, pode trazer muitos benefícios para o desenvolvimento cognitivo, motor e social. Usando estes recursos tecnológicos é possível trabalhar leitura, escrita, imaginação, raciocínio matemático, coordenação motora, cultura, entre outras.

De fato, o potencial destas novas tecnologias, quer no que se refere á natureza dos programas utilizados, quer ás possibilidades de acesso á informação e comunicação disponíveis através da Internet, aliada a sua presença, cada vez mais marcante no nosso dia a dia, torna difícil ignorar o contributo destes novos media no enriquecimento dos contextos de aprendizagem. (AMANTE, 2011, P. 39).

Visto assim, nos dias de hoje as crianças são incentivadas a fazer uso destas tecnologias visto que as mesmas contribuem para seu desenvolvimento, mas mais do que isso são parte do futuro. A cada dia que passa vão estar mais presentes na vida das crianças e lhes oferecer novos recursos de interações e desenvolvimento, sem contar que cada vez mais os recursos tecnológicos vão fazer parte de nosso dia a dia.

\section{METODOLOGIA, APRESENTAÇÃO E ANÁLISE DE DADOS}

A presente pesquisa é vinculada ao curso de Pedagogia, na linha de pesquisa "Teoria e prática pedagógica"; a partir do eixo que discute as tecnologias na educação. Tem como objetivo analisar quais as interações que as crianças de 4 a 5 anos estabelecem no uso dos recursos tecnológicos digitais a partir das falas dos pais de alunos de uma escola de educação infantil particular da cidade de Criciúma/SC. Esta é uma pesquisa de cunho qualitativo, de caráter exploratório, bibliográfica e de campo, tendo como instrumento de pesquisa um questionário.

Quanto à pesquisa de campo, ela resulta na observação de fatos, acontecimentos, manifestações e ações rotineiras, tendo como subsídio a coleta de dados, e posteriormente, uma análise e interpretação para alcançar o objetivo de compreender o problema pesquisado. Segundo Lakatos e Marconi (2010), a pesquisa de campo tem como objetivo conseguir informações e conhecimentos do problema pesquisado. 

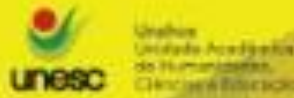

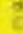

O público alvo da pesquisa foram pais de alunos da Educação Infantil da rede particular do município de Criciúma, de 4 a 5 anos, especificamente de uma turma do préescolar da mesma instituição. A escola se localiza no centro da cidade, foi fundada a 37 anos e atende crianças de classe média, classe média alta. O contato com os pais se deu em consonância com a direção da escola. Após a autorização é que ocorreu a coleta dos dados. Para a coleta dos dados utilizou-se um questionário (Anexo 1) que foram entregues em envelopes individuais juntamente com o termo de consentimento (Anexo 2) para a participação na pesquisa. Foi determinado um prazo de uma semana para que os pais pudessem responder em suas casas. Após este prazo as mesmas foram entregues na escola e devolvidas a pesquisadora. Salienta-se que foram entregues questionários para doze pais, mas um não respondeu, constituindo-se assim 11 sujeitos da pesquisa. Os sujeitos/pais serão identificados como A, B, C, D respectivamente até a letra $\mathrm{K}$, mantendo suas identidades resguardadas. A seguir apresentam-se a análise e a interpretação dos dados.

\subsection{Análise e interpretação dos dados.}

Para melhor responder o problema de pesquisa os dados coletados foram primeiramente organizados por meio de eixos de análise, de acordo com o questionário de pesquisa. São quatro os eixos que serão apresentados a seguir: Brinquedos e brincadeiras preferidos; Crianças e suas tecnologias: recursos e seus dispositivos; acesso a tecnologia; Percepção das contribuições pelos pais.

O primeiro eixo objetivou identificar quais são os brinquedos e brincadeiras preferidos das crianças, de forma geral, sem especificar se eram de base tecnológica ou não. Nas respostas, dos 11 que responderam 04 não mencionaram recursos tecnológicos, os demais citaram o tablet ou o vídeo game como um dos brinquedos preferidos dos seus filhos. Em relação as demais brincadeiras, é importante destacar que apareceram em todas as respostas o quebra-cabeça, bonecos e bonecas, brincadeiras de correr como futebol, pegar e esconder. Verificou-se também, que a maioria, ou seja, 07 casos mencionaram os recursos tecnológicos, o que indica que precocemente as crianças tem acesso aos mesmos, tendo o uso mais como um brinquedo ou brincadeira, o que corrobora com a ideia de Amante (2011, p.114) que diz:

Saberes Pedagógicos, Criciúma, v. 3, nº1, janeiro/junho 2019.- Curso de Pedagogia- UNESC 

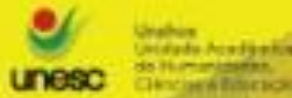

“[...] eles fazem, desde sempre, parte do seu mundo e a sua utilização, ainda que casual, é encarada com toda naturalidade."

Por outro lado, se pode afirmar que, mesmo os recursos tecnológicos serem tão presentes na vida das crianças, em todas as respostas foram citadas também brincadeiras culturalmente tradicionais da infância praticadas ao ar livre, como subir em arvore, correr, futebol, bonecas entre outras. Segundo Volpato (2002, p.19):

[...] parece que o mundo dos brinquedos está marcado por toda parte, pelos vestígios de gerações passadas. Essa percepção levou Benjamin a dizer que a infância tornouse o reservatório dos costumes abandonados pelos adultos.

Também Aries (1981) nos seus estudos sobre história da infância pontua que mesmo com a evolução, as brincadeiras se repetem, chegando assim a conclusão de que os jogos e brincadeiras são importantes para todas as idades e classes. Com as respostas apresentadas podemos perceber que os pais têm buscado incentivar as crianças a não deixarem de lado as brincadeiras ditas tradicionais, de quando crianças.

Desta forma, a pesquisa mostra exatamente o que o autor afirmou, pois, mesmo tendo a tecnologia na forma de brinquedos, os costumes nas brincadeiras passam de geração em geração, pelo menos até este momento as crianças ainda praticam brincadeiras consideradas da geração passada. Para Amante (2011), mesmo com uma onda de entusiasmo pelas tecnologias na infância, as experiências de integração demonstram que o uso destas não diminui a procura por outras atividades, brincadeiras e ou materiais.

No Eixo 2, Crianças e suas tecnologias: recursos e seus dispositivos o objetivo foi identificar quais são os recursos que as crianças tem acesso e utilizam, dentre as seguintes opções: computador; computador e internet; celular; tablet; televisão canal aberto; e televisão canal pago. Também buscou-se verificar quais os dispositivos digitais são os preferidos das crianças, entre estes: softwares, aplicativos para celular e tablet e programa de televisão. Em relação aos recursos tecnológicos mais utilizados pelas crianças, o tablet e o canal pago, aparecem em todas as respostas. Já o computador e a internet são citados por 04 pais e o celular foi o menos citado, usado por 03 crianças. 
Já nos dispositivos digitais preferidos 05 crianças têm acesso a softwares e os utilizam para jogos online. Os aplicativos de celular e tablet são os jogos de passar de fases, filmes e vídeos online como youtube e Netflix. Um dos pais mencionou aplicativos em inglês e outro aplicativos de jogos matemáticos. Nos programas de televisão todos responderam desenhos animados, entre os mais citados foram Masha e o urso, Patrulha Canina, D.P.A.

Verifica-se que diante de um número considerável de possibilidades tecnológicas, há uma variedade de conteúdos a serem explorados. Nesta amostra percebe-se que as crianças exploram desde as tecnologias digitais mais sofisticadas como aplicativos e jogos, bem como a televisão, que ainda é acessada para os desenhos animados. Em relação aos aplicativos há interesse sobre aqueles que desenvolvem a linguagem como inglês e também a matemática. Para Amante (2011, p.113) o jogo contribui [...] para estimular o desenvolvimento cognitivo, social e emocional das crianças. "Ainda, a autora, em relação aos jogos e tecnologias, destaca:

\begin{abstract}
O jogo e a sua natureza está intrinsicamente ligado à cultura. Assim, no mundo de hoje, profundamente tecnológico, para além das formas tradicionais de jogo, as crianças passaram a ser confrontadas com outros tipos de atividades desta natureza, designadamente com formas tecnológicas de jogo, como os videojogos e os genericamente designados ‘jogos de computador’. (AMANTE, 2011, p.113-114).
\end{abstract}

Contudo, vale destacar, de acordo com Amante (2011) a necessidade de uma atitude crítica na utilização dos jogos, pois é fundamental que se estabeleçam critérios de escolha considerando o perfil e o desenvolvimento cognitivo das crianças.

O Eixo 3 abordou o Acesso à tecnologia na infância, tendo como objetivo verificar com que idade as crianças têm acesso aos recursos listados no Eixo 2, e quem possibilitou esse acesso. Todos os sujeitos responderam que foi por meio dos pais que as crianças tiveram acesso aos recursos tecnológicos e desde muito pequenos, um (01) dos sujeitos respondeu que o acesso foi possibilitado desde o dia em que nasceu, os demais responderam que o acesso se deu entre 4 e 5 anos de idade. Segundo Amante (2011, p.114):

Não é, pois, de se admirar que as crianças, mesmo as mais novas, se sintam particularmente atraídas pelos ecrãs de computador e pela possibilidade de interagir com esse instrumento. Para as crianças os recursos que designamos como "Novas Tecnologias" não são de fato "Novos". Tendo, maiores ou menores oportunidades de contacto com estes meios, os computadores não lhe são estranhos, eles fazem,

Saberes Pedagógicos, Criciúma, v. 3, nº1, janeiro/junho 2019.- Curso de Pedagogia- UNESC 
desde sempre, parte do seu mundo e a sua utilização, ainda que casual, é encarada com toda a naturalidade.

Podemos assim perceber que desde muito cedo as crianças têm acesso a estes recursos tecnológicos, tornando-os parte de sua rotina tanto para brincadeiras quanto para o seu desenvolvimento cognitivo, motor e social, e com toda essa familiarização seu uso acaba se tornando cada vez mais fácil.

O Eixo 4 analisou a Percepção dos pais sobre infância e tecnologia. Esse eixo buscou evidenciar, na percepção dos pais, diante do acesso tecnológico que as crianças têm, quais as contribuições destas para o desenvolvimento ou não na infância. Também se buscou compreender na opinião dos pais, como percebem a infância na contemporaneidade, considerando a inserção das crianças na sociedade tecnológica.

Com relação as contribuições ou não que o uso trás para o desenvolvimento os pais citaram: agilidade, desenvolvimento do cérebro e coordenação motora, conhecimento dos aspectos de funcionamento da tecnologia, aprendizagem da língua inglesa, ampliação dos conhecimentos gerais, acesso a outras culturas, superação de limites, enfrentar desafios e frustações, desenvolver visão estrategista, instigar uma visão individualizada, como distração, despertar da curiosidade, concentração, raciocínio rápido e lógico, e criatividade.

Para melhor exemplificar, dentre as respostas destacamos quatro (04):

\footnotetext{
Acredito que não devem substituir as brincadeiras lúdicas tradicionais, mas se usada com limites, desperta a curiosidade, melhora a concentração, coordenação e para essa geração pode ser um momento de distração e relaxamento. (SUJEITO H) Acredito que o recurso tecnológico contribui de forma positiva a criança superar limites, enfrentar desafios e frustações, e desenvolver uma visão estrategista. Por outro lado, instiga uma infância individualizada, que se não houver cuidado a criança terá tendência de estar sempre reclusa em casa. (SUJEITO E)

$\mathrm{Eu}$ acredito que contribui para ampliar os conhecimentos da criança, é um mundo inteiro de informações, possibilidades que estão ali em uma tela, acessível a um toque. Mas lógico, que é preciso acompanhar a criança, conversar, guia-la. As regras e os limites para utilização devem ser claras, assim evitando os excessos que podem ser prejudiciais. (SUJEITO B)

Esses recursos tecnológicos são mais uma opção de distração para crianças, desde que seu uso não seja na hora das refeições. Por muito tempo consegui escovar os dentes da minha filha enquanto ela se distraia com desenhos que consegue escolher no tablete. Penso que a maior contribuição é a vasta opção de programas, que não se repetem e são adequados para todas as idades. (SUJEITO G)
}

Saberes Pedagógicos, Criciúma, v. 3, nº1, janeiro/junho 2019.- Curso de Pedagogia- UNESC 
A partir desta última resposta podemos então perceber também o quanto o o uso das tecnologias ou o excesso delas podem de alguma maneira afetar de maneira não tão positiva a criança. Ao tratar das relações entre tecnologia e desenvolvimento de linguagem na idade pré escolar, Amante (2011) a partir das ideias de diversos autores destacou as seguintes contribuições, o encorajamento à produção de discursos mais complexos e fluentes através dos jogos; o estimulo a usar a linguagem quando utilizam programas abertos que estimulam a exploração e a fantasia, e ao relatarem enquanto desenham ou escrevem,; elaborar historias através dos desenhos criados no computador; também pontuam que a interação com as tecnologias aumenta a comunicação verbal e a colaboração entre as crianças.

Já quando questionadas como percebem a infância na contemporaneidade, considerando a inserção das crianças na sociedade tecnológica a maioria se mostrou bastante preocupada quanto ao excesso destas tecnologias podem privar seus filhos de uma infância com brincadeiras e socialização.

\begin{abstract}
De fato, é impossível criar filhos hoje fora do mundo tecnológico, seria imprudência dos pais privar totalmente a criança de conhecer esse mundo "paralelo". os pequenos possuem uma sabedoria natural, instintiva que os orienta nesse avanço, não há como retroceder, seria como colocar o filho dentro de uma bolha. Há que se ter, é claro, limites por parte dos pais, controlando os acessos e uso de tecnologia, pois hoje, o bicho papão é virtual, uma vez conectado, estão expostos precocemente a questões que a minha geração conheceu muito mais tarde. Os adultos precisam limitar, orientar e dialogar a respeito com os pequenos. (SUJEITO H)
\end{abstract}

Por outro lado, os pais reconhecem a importância e contribuições que o uso dessas tecnologias podem trazer para seus filhos conforme citado anteriormente. Segundo Amante (2011, p.53)

[...] a tecnologia informática, designadamente as possibilidades disponibilizadas pela Internet, pode proporcionar aos educadores/professores e as crianças oportunidades únicas de acesso as informações e locais muito diversificados, que podem seguramente constituir-se como poderosos recursos educacionais.

Ao finalizar a apresentação das quatro categorias deste estudo evidenciamos que há pontos de convergência nas respostas apresentadas, bem como algumas variações em relação as respostas, mas a grande maioria vê de maneira positiva o uso destes recursos e o 

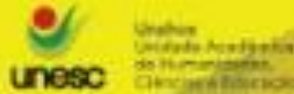

quanto eles contribuem para o desenvolvimento de seus filhos, mas todos ressaltam que o uso desses recursos precisa ser vigiado e limitado pois assim temem afetar a parte social visto que muitos se isolam do resto a passam a ficar muito tempo em frente ao computador, perdendo assim de alguma forma o gosto e prazer por brincadeiras tradicionais e convívio com demais pessoas.

\section{CONCLUSÃO}

Ao concluir este trabalho é importante destacar o quanto a imagem da criança vem mudando ao longo dos anos, de forma a integrar todo o seu desenvolvimento. Diante de um mundo onde a tecnologia se faz cada vez mais presente na vida de todos, com as crianças não poderia ser diferente, a cada dia novas ferramentas tecnológicas surgem de maneira a contribuir para o desenvolvimento tanto motor, como cognitivo e social deles.

Esta pesquisa nos permitiu identificar que os recursos tecnológicos estão muito presentes no desenvolvimento de crianças entre 4 e 5 anos de idade, sendo eles tablet, celular, computador, internet e televisão canal pago e aberto. Através desses recursos e da infinidade de possibilidades permitidas por meio dessas tecnologias como aplicativos, vídeos, softwares e programas de televisão, os pais tem notado de forma positiva essa interação. Ao relatarem de que maneira seus filhos fazem uso e quais seus recursos preferidos chamou atenção a utilização para jogos matemáticos e de outras línguas e culturas, nos mostrando o quanto a ludicidade contribui para o interesse e a aprendizagem.

O uso destes recursos thes foi permitido desde muito cedo, nos primeiros anos de vida e propiciado pelos pais, como relataram os mesmos, tornando assim o uso não só para lazer e distrações, mas também como um apoio ao desenvolvimento cognitivo, social e emocional das crianças.

Foi possível analisar o reconhecimento dos pais diante da importância dos recursos tecnológicos utilizados sendo que a maioria diz compreender a importância das tecnologias nos dias de hoje, o quanto cada dia mais ela esta presente na vida de todos, e que privando seus filhos disso estariam os privando de novas descobertas. Mas ao mesmo tempo relatam o quanto ficam preocupados com o uso excessivo destes recursos, e os malefícios que 


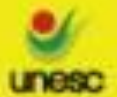

podem causar. Preocupam-se com o quanto pode afetar a parte social e por isso continuam a incentivar as brincadeiras tradicionais como, correr, pular corda, brincar de bonecas e subir em árvores.

Concluímos então a pesquisa percebendo que cada vez mais a utilização dos recursos tecnológicos está integrada ao cotidiano das famílias e consequentemente das crianças. Seu uso na maioria das vezes, é percebida pelos pais como possibilidades de contribuir com o desenvolvimento e a aprendizagem, contudo há ainda os pais que usam esses recursos atrativos para impor disciplina e limites, ou seja como uma troca para que as crianças fiquem quietas, tomem banho, escovem os dentes, etc., o que pode ser um problema futuramente.

Sendo assim, compreende-se que a tecnologia cada vez mais faz parte do dia a dia das crianças de modo que contribui para que essas interações lhes proporcionem novas experiências, e mesmo que estes recursos lhes proporcionem momentos de descontração e lazer, ainda na maioria das vezes são substituídos por brincadeiras tradicionais.

\section{REFERÊNCIAS}

AMANTE, Lúcia. As tecnologias digitais na escola e na educação infantil. Pinhais: Melo, 2011. $176 \mathrm{p}$.

ARIÈS, Philippe; FLAKSMAN, Dora. Historia social da criança e da família. 2.ed. Rio de Janeiro: LTC, 1981. 279 p.

BENJAMIN, Walter. Reflexões: a criança, o brinquedo, a educação. São Paulo: Summus ed., $1984.119 \mathrm{p}$.

KISHIMOTO, Tizuko Morchida (Org.). Jogo, brinquedo, brincadeira e a educação. 5.ed. São Paulo: Ed. Cortez, 2001. 183 p.

LAKATOS, Eva Maria; MARCONI, Marina de Andrade. Fundamentos de metodologia científica. 7. ed. São Paulo: Atlas, 2010.

MALUF, Angela Cristina Munhoz. Brincar: prazer e aprendizado. 3. ed. Petrópolis, RJ: Vozes, 2004. 111 p.

\section{TAVARES, Neide Rodriguez Barea. História da informática educacional no Brasil}


observada a partir de três projetos públicois. São Paulo, SP. Disponível em:

<http://www.apadev.org.br/pages/workshop/historiaInf.pdf > Acesso: 10 ago. 2017

VOLPATO, Gildo. Jogo, brincadeira e brinquedo: usos e significados no contexto escolar e familiar. Florianópolis: Cidade futura, 2002.

VOLPATO, Gildo. Jogo, brincadeira e brinquedo: usos e significados no contexto escolar e familiar. Florianópolis: Cidade futura, 2017. 